\title{
OBSTETRIC OUTCOME IN VAGINAL BIRTH AFTER PREVIOUS CAESAREAN PREGNANCY (VBAC)
}

Chourasia Sudha, Bamnia Raksha, Jain Veena, Wadhwani Rekha.

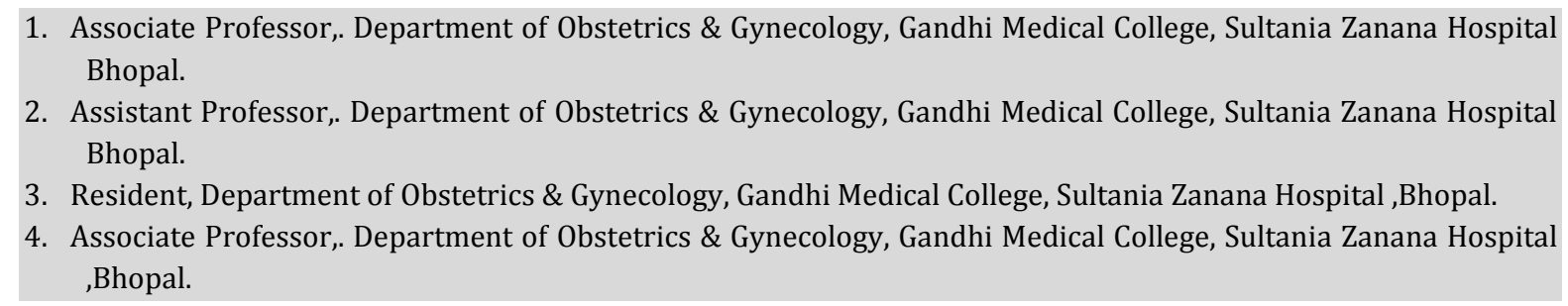

\section{CORRESPONDING AUTHOR:}

Dr. Raksha bamnia, Flat no. 7, classic apartment, Ridge road, Idgah hills, Bhopal.

E-mail: manvi_dr@yahoo.co.in

ABSTRACT: AIMS \& OBJECTIVES: - To study the factors affecting success of vaginal birth after caesarean section \& to study maternal \& fetal outcome after VBAC. METHODS:- The study included 248 women with previous one caesarean section at 38 completed weeks of gestation, without obstetric complications, and were given trial of labor. Progress of labor, mode of delivery and maternal and fetal outcomes were noted and analysed. RESULTS: Out of 248 cases $66.1 \%$ delivered vaginally and repeat caesarean section was done in $33.9 \%$.Out of 138 cases of Previous caesarean done for non reassuring fetal heart rate,74(53.6\%) delivered vaginally. CONCLUSION: Good selection of cases and meticulous supervision during labor helps in successful VBAC.

INTODUCTION: Pregnancy with previous caesarean section is quiet prevalent condition .This is due to liberalization of primary caesarean section for non-recurrent indication. Caesarean section rates has increased from $21.8 \%$ in $1993-1994$ to $25.4 \%$ in $1998-1999^{1}$, leading to increasing number of women with previous caesarean section in subsequent pregnancy and labor.

Post caesarean pregnancy is a high risk case and had scrupulous supervision during antenatal period and labor. The dictum "once a caesarean, always caesarean" no longer applies. Women who have previous caesarean delivery can safely attempt a trial of labor to have vaginal delivery in subsequent pregnancies. Vaginal birth after caesarean (VBAC) is possible but is associated with risk and need supervision.

Caesarean section is associated with maternal morbidity. Maternal complications include hemorrhage, infection, pulmonary embolism, DVT. Major benefit of VBAC is reduction in maternal morbidity, avoiding uterine incision, lower cost. VBAC is associated with various complications and risks such as scar dehiscence, rupture uterus, perinatal morbidity and mortality, hysterectomy, unsuccessful trial of labor requiring emergency caesarean section.

Major factors influence the success of TOL such as indication of previous caesarean section, previous normal delivery, site \& type of scar, no. of caesarean section. Our study was done to know the factors affecting \& obstetric outcome in vaginal birth after previous caesarean section. Trial of 


\section{ORIGINAL ARTICLE}

labor after caesarean (TOLAC) is a planned attempt to labor who have previous caesarean delivery. A VBAC is a "successful" trial of labor resulting in a vaginal birth.

MATERIALS \& METHODS: A prospective randomized study during 1 year period was carried out at Sultania zanana hospital, Bhopal. 248 cases of previous caesarean section were taken, who were admitted in routine or in emergency and who underwent trial of labor. Trial of labor was given to women who have completed 37 weeks with previous one lower segment caesarean section, with caesarean section done for non recurrent indication, pelvis adequate for baby \& had no obstetric complication.

Women with previous two caesarean section, previous classical C-section, malpresentation \& with obstetric complication in present pregnancy were excluded.

Complete history, especially obstetric history, indication of previous caesarean, operative details if available, associated \& postoperative complications in previous caesarean section were noted.

Appropriate discussion about maternal \& perinatal risk was done. Informed consent was taken. Facility for fully equipped OT, availability of anesthesia, pediatrician \& efficient surgical unit was ensured. During labor vitals were recorded, partogram maintained, frequent FHS \& uterine activity noted, signs of scar dehiscence were looked frequently. Mode of delivery whether vaginal or repeat caesarean section, maternal \& perinatal outcome were studied.

RESULTS: This study included 248 cases of pregnancy with previous LSCS, who were given trial of labour. $64.6 \%$ of cases were in the age group of $20-25 \mathrm{yrs}, 30.4 \%$ in between $26-30 \mathrm{yrs}$ and $5 \%$ between 31-35yrs and 0.8\%were above 36yrs of age. Majority of cases were para 1(71\%), para 2 were $(20.2 \%)$, para 3 were7.2\%and para $4 \&$ above were $1.6 \% .54 .8 \%$ cases were unbooked. Table no.1 shows the incidence of mode of delivery in present pregnancy, compared with indication of previous caesarean section. Out of 248 cases who had undergone trial of labor, $66.1 \%$ delivered vaginally and repeat caesarean section was done in $33.9 \%$.

TABLE NO 1: shows that incidence of vaginal delivery was more in the case of non reassuring fetal heart rate in previous caesarean (53.6\%).However with previous non recurrent indication (breech, NPOL,CPD),repeat caesarean section were more(55.2\%,72.7\%\& 87.5\%) respectively. Cases who had vaginal delivery before or after previous caesarean section were $114.56 \%$ had caesarean delivery $\& 44 \%$ had vaginal delivery.

In vaginal delivery group there was one perinatal mortality. In repeat caesarean section there were five perinatal mortality. There were 14 cases of scar dehiscence taken for caesarean section. True scar dehiscence was found in two cases. There was no maternal mortality.

There were 2 cases of rupture uterus, came in $2^{\text {nd }}$ stage of labor \& delivered vaginally. It was complete rupture on laparotomy. In one case scar repair was done and in other case broad ligament hematoma was found and hysterectomy had to be performed.

DISCUSSION AND CONCLUSION: The primary caesarean section rate has increased to an alarming extent and thereby increasing incidence of repeat Caesarean section rate. This is because of reluctance to give trial of labor in pregnancy with previous caesarean pregnancy, difficulty in monitoring of labor, assessing integrity of scar, patient coming late in labor. 
This study showed that $66.1 \%$ of cases delivered vaginally after trial of labor,which is comparable of $60-80 \%$ of successful VB AC in candidates for trial of labor after caesarean ${ }^{2}$. In our study incidence of vaginal delivery was more in the case of non reassuring fetal heart rate in previous caesarean. However contrary to other studies $5,6,7,9$, our study showed that repeat caesarean section were more with previous non recurrent indication(breech, NPOL,CPD) .This may be due to patient coming late in labor, reluctance to give trial and patient preference for caesarean section. In many studies, prior successful VBAC was found to be associated with success of trial of labor. Many authors reported history of prior spontaneous vaginal delivery as important determinant for success in VBAC $5,8,9$. But our study failed to show that.

Trial of labor after caesarean (TOLAC) to attempt VBAC is acceptable option for women who had undergone one prior caesarean delivery with low transverse uterine incision, and there are no other conditions that would normally require a caesarean delivery ${ }^{3}, 4$. Neither repeat caesarean section nor trial of labor is risk free, but if successful, it offers many advantages in terms of reduced maternal and fetal complications.

Physicians should have knowledge of factors having good outcome before counseling mothers so that failure rates decrease. VBAC is a safe practice as long as it is offered with proper selection of candidates with factors having a high success rate.

TABLE 1: Incidence of mode of delivery in present pregnancy as compared with indication of previous caesarean section

\begin{tabular}{lllll}
\hline s.no. & Indication of previous caesarean & Total & Vaginal & Repeat caesarean \\
& section & no. & delivery & section \\
& & & & \\
\hline 1. & Non reassuring fetal heart rate & 138 & $74(53.6 \%)$ & $64(46.3 \%)$ \\
2. & Breech & 38 & $17(44.7 \%)$ & $21(55.2 \%)$ \\
3. & NPOL & 44 & $12(27.2 \%)$ & $32(72.7 \%)$ \\
4. & CPD & 24 & $03(12.5 \%)$ & $21(87.5 \%)$ \\
5. & Postdate pregnancy & 02 & $01(50 \%)$ & $01(50 \%)$ \\
6. & oligohydramnios with IUGR & 02 & $01(50 \%)$ & $01(50 \%)$ \\
\hline
\end{tabular}

\section{REFERENCES:}

1. Jodie MD, Caroline AC, Janet EH, Ross RH, Jeffery SR. Vaginal birth after Kambo I, Bedi N, Dhillon BS, et al. A crtical appraisal of caesarean section rates at teaching hospitals in India. Int. J Gynecol Obstet.2001; 79:151-8. 


\section{ORIGINAL ARTICLE}

2. Mozurkewich EL, Hutton EK. Elective repeat caesarean delivery versus trial of labor: A meta-analysis of the literature from 1989 to 1999. Am J Obstet Gynecol 2000:183:1187.

3. American College of Obstetricians and Gynecologists. ACOG Practice bulletin no. 115: Vaginal birth after previous caesarean delivery. Obstet Gynecol 2010; 116:450.

4. National Institute of Health Consensus Development Conference Statement vaginal birth after caesarean: new insights March 8-10, 2010. Semin Perinatol 2010; 34:351.

5. Up-to-date version 16.3, vaginal birth after cesarean delivery. 2008.

6. Boulvain M, Fraser WD, Brisson-Carroll G, Faron G, Wollast E. Trial of labor after caesarean section in sub-Saharan Africa: a meta-analysis BJOG. 1997; 104:1385-1390. doi: 10.1111/j.1471-0528.1997.tb11008.x.

7. Caesarean. BMC Childbirth and Pregnancy. 2007; 7:17. doi: 10.1186/1471-2393-7-17.

8. Taj G, Sohail N, Cheema SZ, Zahid N, Rizwan S. Review of Study of Vaginal Birth After Caesarean Section (VBAC) Annals. 2008; 14(1):13-16.

9. Cecatti JG, Pires HMB, Faúndes A, Duarte Osis MJ. Factors associated with vaginal birth after previous cesarean section in Brazilian women. Rev Panam Salud Publica. 2005;18(2):107113. 